\title{
MJN FAMILY SUPPORT AND CHURCH ATTENDANCE AS PREDICTORS OF ELDERLY'SQUALITY OF LIFE AT SOUTHERN MINDANAO
} \author{
Julius M. Mirafuentes ${ }^{1}$, Dacilo M. Adap, Jr. ${ }^{4}$ \\ ${ }^{1}$ College of Health Sciences, Mindanao State University, Philippines \\ ${ }^{2}$ College of Nursing, Cebu Normal University, Cebu City, Philippines \\ ${ }^{3}$ College of Arts and Sciences, Mindanao State University-Sulu, Philippines \\ ${ }^{4}$ Department of Education, Autonomous Region in Muslim Mindanao, Philippines \\ *Corresponding Author's Email: pangandamanhamdoni@gmail.com
}

Hamdoni K. Pangandaman ${ }^{1 *}$, Maria Agnes Ortega ${ }^{2}$, Magna Anissa A. Hayudini ${ }^{3}$, Nursidar P. Mukattil ${ }^{3}$,

\begin{abstract}
The association between spiritual activities and quality of life (QoL) has received scholarly attention from different religious affiliation. This study centers on examining the interrelationship of tripartite variables church attendance, family support and quality of life among elderly at southern part of Mindanao, Philippines through path analysis approach as multivariate research. A reliable $(\alpha=0.94)$ and valid 13-item Family Support Scale (FSS) and WHOQOL-BREF 26 -items questionnaire $(\alpha=0.88)$ has been adapted to gather data from stratified randomly selected 50 elderly participants. It shows that elderly have 66 to $78 \%$ church attendance with a mean of $72 \%$, have some family support $(M=72.42)$ and high QoL $(M=79.90)$. QoL is significantly influence by church attendance and family support $\left(R^{2}=0.20\right)$. Then, family support significantly influences church attendance and so a significant mediator between family support and QoL $\left(R^{2}=0.17 ; \beta=0.131\right.$; sig $=$ 0.036). The path analysis model conveys that the association between family support and church attendance and both as an independent variable are indispensable for the promotion of Filipino elderly's QoL. It has important place for consideration in the plan of care. Other variables are recommended for in-depth inquiry to promote a holistic elderly's QoL model.
\end{abstract}

Keywords: Church Attendance; Family Support; Quality of Life; Elderly; Descriptive-Predictive

\section{INTRODUCTION}

The association between spiritual or religious activity and quality of life (QoL) has received scholarly attention from different religious affiliation. Among elderly Christian believers, church attendance partly reflects a tangible representation of their level of spirituality which they may be practiced with support from significant others. Accordingly, family that supports elderly spirituality has been linked with better health and less likelihood of diseases (Monserud \& Markides, 2017; Suk Sun, Kim-Godwin \& Koenig, 2016). Studies show that elderly who regularly engage in religious practices experience psychophysiological health benefits including less loneliness which promotes positive life outlook and sense of belongingness, improves mood, reduce blood pressure, better cognitive and immune system functioning and physical mobility (Hill et al., 2006; Kim et al., 2015; Stecz \& Kocur, 2015;
Tariga, 2016). Given that religious attendance show health benefits in myriad ways, it is not startling to discover that religious engagement may also predict better quality of life for elderly in general (Oates, 2016).

The inkling that religious attendance could promote quality of life is largely consistent with an increasing number of researches about socio-spiritual engagement and health issues and concerns in late life. For instance, some studies show that being socially connected and active, has strong social support for religious undertaking, which are essential antecedents for healthy psychophysiological aging (Chaves \& Gil, 2015; Moeini, Sharifi, \& Zandiyeh, 2016; Stecz \& Kocur, 2015; Suk Sun, Kim-Godwin \& Koenig, 2016). Attending churches also demands physical mobility that promote exercise and so physical health, especially for those with disability be done with help and assistance of a family member. Consequently, it 
promotes an opportunity to meet other people in the community necessary for building social health.

Moreover, evidences suggest that in later life individuals have high tendency of engagement in religious or spiritual endeavors, and so, has been highly associated with surging prevalence of spiritual and religious activity worldwide (Ellor, 2013; Suk Sun, KimGodwin \& Koenig, 2016; Tariga, 2016). In the United States, more than half of population of elderly has usual routine of attending church activities and services at least weekly (Ellor, 2013). It could be presumed as tangible measure of spirituality as more attendance reflects higher spirituality. This can be reflected among catholic Christians, including Filipinos, whose values orientation and traditional beliefs are strongly connected with actively attending religious activities. It has been a belief that attending church is a direct form of worship that increases relationship with the creator and satisfies spiritual needs and well-being (Banerjee et al., 2014; Blace, 2012). So, elder who are more devoted towards the church have satisfied their spiritual needs than those who does not attend.

One of the best components that promotes realization of spiritual practices and other religious engagement is family support. It encompasses spiritual, social, financial, moral, psychological, along with financial or economic support which are all essential in the fulfillment of elderly's activity of daily living (ADL). Family member/s that are supportive to their elderly shown to have high rates of church attendance and engagement in religious activities (Ellor, 2013). Socially supportive family with positive attitude towards religious engagement are found to be proactive in attending church activities regularly and claims to have been in good health (Malone \& Dadswell, 2018).

However, though religious engagement has been sometimes assessed through spiritual health of aging globally, the interrelationship of family support and religious attendance as important domain and a prerequisite of the former is of a less concern and unexplored and so need further research. Western culture and their religion has been the large focus of research concerning family phenomenon and spirituality of elderly ( Suk Sun, Kim-Godwin \& Koenig, 2016). So it lacks picture in the context of Filipino. Considering the several number of cultures in Asian countries, like Philippines, a country for various religious affiliations, association between church attendance and family support as predictors of elderly quality of life is a unique contribution.

\section{Problem Statement and Hypothesis}

This research aims to discover the influence of family support towards church attendance and as both predictors of quality of life of elderly at southern Mindanao. So, it is hypothesized that Ha1: Family support positively affects church attendance; Ha2: Family support positively affects quality of life; Ha3: Church attendance positively affects quality of life; Ha4: Church attendance significantly mediates the effect of family support towards quality of life.

\section{Framework}

Figure 1 below depicts the interplay of the three variables in this study: family support, church attendance, and quality of life. The framework proposes that Filipino elderly as family-oriented culture have variety of needs, which is composed of, but not limited to psychological, physical, social, financial, emotional and spiritual factors that defines QoL could be dependently influenced by support emanated from the elderly's family. The extent on which the family provide supports to elderly defines partially the extent of QoL.

Moreover, it distinctly illustrated that church attendance interplay with the family support and QoL as mediator variable. Church attendance as operationally used in this study is the physical presence of attending regular schedule catholic church activity every Sunday. It is based on the premise that spirituality level of individual elderly uniquely varies, and as such, elderly with high level of spirituality may demand more attendance at church which requires an extent of support from the family due to some psychophysiological problems and limitations. The degree of church attendance then could mediate or change the indirect effect of family support towards quality of life. In the model, both family support and church attendance as individual variable that could directly influence or affect quality of life.

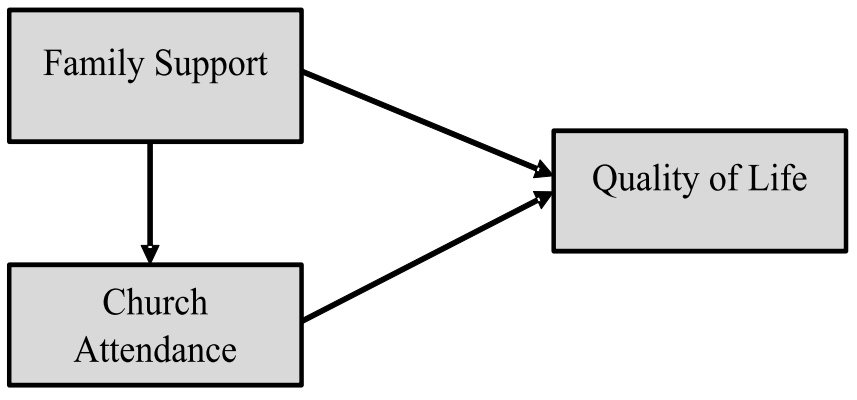

Figure 1: Conceptual Framework of the Study 


\section{LITERATURE REVIEW}

The global population of ageing (60 years old \& above) in the year 2020 exceeds the number of children 5 years of old and below and has been predicted to exponentiate, from 900 million in 2015 to 2 billion in the year 2050. In Asia, the population of over 65 years old $(24 \%)$ is almost tripled compared to that under 15 years of age ( $9 \%)$. Countries with a share of population aged 65 years and older between $19 \%$ to $26 \%$ are Japan, Italy, Germany, Portugal, Finland, Bulgaria, Greece, Sweden, Latvia and Denmark (IIASA, 2018). In the Philippines, the population of senior citizens or 60 years and older has increased from $7.5 \%$ in 2015 (about 7.55 million) to $8.2 \%$ in 2019 (about 12.84 million) and expected to flux at 9\% (about 13 million) in the full year of 2020. By region, the most populated of senior citizen or elderly live in the region IV-A or Calabarzon (14.4 million), National Capital Region (12.8 million), and Central Luzon (11.2 million). In region IX or Zambonga Peninsular, it has 3.6 million of elderly or senior citizen in the year 2015 and projected to be about 4.5 million in the full year of 2020 (Philippine Statistics Authority, 2017).

As the population of ageing grows significantly, the multitude challenge in socio-spiritual engagement and health issues and concerns in late life and other factors to meet their quality of life becomes vital (Humphreys, 2012). World Health Organization (WHO) described quality of life as the "individual's discernment of their position in life in the context of the culture and values systems in which they live and in relation to their goals, expectations, standards and concerns" (Nejati et al., 2008). It is a wellness experienced as a result from a combination of functional, physical, social and emotional factors (McHorney et al., 1994). The level of spirituality is high among advanced aging than other age group because it promotes quality of life as it helps to discover and promote the use of coping strategies in dealing with their diseases, its prognosis, symptoms, and the concept of dying (Agli, Bailly \& Ferrand, 2015). Also, elderly practices spirituality affiliated in a specific religion through attending or participating in a church or religious gathering to promote peace and sense of purpose (de Blot, 2011; Lewis, 2001).

In the United States, more than half of ageing population attending churches regularly has been reported to promote sense of wellness in their life's journey (Ellor, 2013). In a study among Mexican elderly widows shows that frequent church attendance served as protective factor against increasing depressive symptoms of pre-and-post widowhood (Monserud \& Markides, 2017). Then, Benrjee et al., (2013) scientific inquiry in a community at
Canada reported that older persons attending churches more than once a week has been inversely associated with health problems including coronary heart disease (CHD), diabetes and high blood pressure because it provides social support and activities, enhances mental health, and promotes health and lifestyle behavior. The same findings in a study at municipality in southwestern Finland of 449 men and 631 women elderly shows that women have frequent church attendance than men and frequent church attendance has found to have significant relationship $(p=0.002)$ with lower mortality rates. As recorded that $48 \%$ of non-attenders, $38 \%$ of infrequent attenders, and $34 \%$ of frequent attenders had died by the end of the follow-up (Teinonen et al., 2005). According to Tariga (2016), late life individuals have high tendency of engagement in religious or spiritual endeavors evinced by prevalence of older persons engagement with spiritual and religious activity worldwide.

In the context of Filipinos spirituality in the Philippines, their elderly are inherently religious and this nature follows faith in God based on their life experiences and life's meaning that grows a sense of security and hope in the life after death (Mamauag, 2019). They preferred to closeness from God, at church as God's home, to enable healthier understanding for better concentration on God's words which portrayed as a sequential course of connection coined as G-O-D, refers to as: Course of Getting involved, Outcome identification, and Deeper connection (de Guzman et al., 2009). Seemingly, researches both locally and globally about church attendance supports a thread with elderly's quality of life.

However, due to some limitations in the psychophysical functionalities of elderly, any help and or assistance from significant others, often family members, could help to attain partial or possibly optimum functionality and well-being or quality of life (Chaves \& Gil, 2015; Moeini, Sharifi \& Zandiyeh, 2016; Stecz \& Kocur, 2015; Suk Sun et al., 2016). Family is an essential part of everyone's life. For elderly, family support is very important in their quality of life particularly in the aspect of social support. Study shows that involving family member/s in actively caring elderly has found to enhance social support. Having a solid connection with family members such as their children, grandchildren and other significant family members of elderly can help to satisfy and achieve cravings for human interaction (Gurung \& Ghimire, 2014). Promoting activities and sense of socialization among elderly through a supportive family has found to promote positive views and practice towards spirituality 
and religion (Noronha, 2015). Family support has a different forms and components which include social, psychological, physical, financial, spiritual, moral and even advocacy. Any alteration either in one or more or in combination could influence the elderly's capacity in attaining a sense of well-being and quality of life (Gurung \& Ghimire, 2014). A very supportive family in the completion or attainment of alterations or inconsistencies of any of the components has found and claimed to have a better life with healthy and peaceful ageing journey (Chappell, 1991). Similarly, overcoming challenges in the journey of ageing becomes more meaningful to those who have supportive family (Noller, Feeney \& Peterson, 2013).

As Filipinos are oriented in practicing close familyties, it is expected that family members particularly those providing support and care to their aged dependent family members (Carlos, 1999; Uddin \& Bhuiyan, 2019). The traditional family support in Filipino for elderly family members differs from other nationalities in other countries, but urbanization drive closer to the situation to send them at home for the aged facilities (Domingo \& Asis, 1995; Uddin \& Bhuiyan, 2019). A closer look in the family support in relation to the spirituality of Filipino elderly through church attendance and its connection to their quality of life seems lacking. Most researches conducted were explorations on the meaning and purpose of elderly's quality of life which were insufficiently supported by reports of its association to the former (Carlos, 1999; Mamauag, 2019; Tariga, 2016).

\section{METHODOLOGY}

This study used descriptive predictive research design to describe the investigated variables and to derive significant influence of exogenous to endogenous variable. It was conducted in five different churches at southern Mindanao particularly in the province of Zamboanga del Sur. All of the churches have a regular weekly church activity after attaining permission from the office and head of each church. The inclusion criteria for participants of the study that has been considered were: (1) elderly who were verbally admitted and were present during three consecutive Sundays church; (2) 60 years of age or above; (3) being accompanied by his/her family member in attending the church; (4) able to understand local/vernacular language or Tagalog; and, (5) given his/her consent to participate in the study . There were ten (10) elderly participants from each catholic church at the Municipality of Tigbao, San Miguel, Dumalinao, and Pagadian City (2 churches).
Therefore, through stratified sampling there were a total of fifty (50) participants in this study.

Church attendance has been assessed by asking the participants if he/she has been attending regular church mass gathering in four consecutive weeks within a month. The researcher explained that this does not equate level of spirituality but a mere attendance for research purpose only. Family support has been assessed though the use of an adapted highly reliable (Cronbach $\alpha=0.94$ ) and valid questionnaire, the 13-item Family Support Scale (FSS) for elderly questionnaire (Uddin \& Bhuiyan, 2019). Then the quality of life has been measured through an adapted questionnaire of the World Health Organization Quality of Life (WHOQOL) - BREF that is composed of 26 -items in a 5-point Likert scale type format that has been used in Asian countries (Suárez, Tay, \& Abdullah, 2018) and particularly shown high significance of reliability result in all domains (sig. $=0.001 ; \alpha=0.88$ ) in a study conducted for Filipino older persons in the Philippines (de la Vega, 2015). The researcher observes ethical consideration through obtaining permission from study participants and the institutions involved. Consultation made with ethics committee approved the conduct of this study.

Data result of this study was statistically annalysed through path analysis, a statistical model used to evaluate causations through examining the relationships between QoL as dependent variable and family support and church attendance as independent variables. Data in this study has been facilitated for analysis and interpretation through computer software including IBM Statistical Package and Service Solution (SPSS) version 23 and analysis of moment structures (AMOS).

\section{RESULTS AND DISCUSSION}

The result of this study is presented and discussed based on the arrangement presented in statement of the problem and hypothesis. Results of this study are carried out in a form of table.

\section{Table 1: Profile of the Elderly as Participants}

\begin{tabular}{|c|c|c|c|}
\hline Variables $(n=50)$ & Mean & \begin{tabular}{c|} 
Std. \\
Deviation
\end{tabular} & $\begin{array}{c}\text { Descriptive } \\
\text { Interpretation }\end{array}$ \\
\hline Church Attendance & \multirow{5}{*}{0.725} & \multirow{5}{*}{0.448} & \multirow{5}{*}{$\begin{array}{l}\text { Above than national } \\
\text { church attendance } \\
\qquad(>58 \%)\end{array}$} \\
\hline Week $1(37 / 74.0)$ & & & \\
\hline Week $2(39 / 78.0)$ & & & \\
\hline Week $3(33 / 66.0)$ & & & \\
\hline Week $4(36 / 72.0)$ & & & \\
\hline Family Support & 72.42 & 13.994 & Some Support \\
\hline Quality of Life (QoL) & 79.90 & 14.846 & High QoL \\
\hline
\end{tabular}


The data in the Table 1 shows that elderly have 66 to $78 \%$ church attendance with a mean attendance of $72 \%$ above than $60 \%$ based on the study conducted by Monserud \& Markides (2017) among Mexican American older persons and the 58\% Philippines church attendance (Pew Research, 2013). This means that elderlies are more inclined towards spiritual activities than other age group because advancing age have more experiences in life to reflect on life in the hereafter with Gods mercy (Mamauag, 2019). However, some are unable to maintain a complete attendance (about 30\%) at church in four weeks or a month because of associated problems and or limitations in the physical mobility, distance of church at home, and family support though they have high level of spirituality (Agli et al., 2015). It implies that family support for them is crucial to overcome problems or limitations of elderly to possibly satisfy spiritual needs or desires, as reflected that it became normal routine for them. This is supported by studies among African-American (Ellor, 2013) and Filipino older persons (de Guzman et al., 2009). Accordingly, practicing spirituality through attending church promotes a sense of security and hope in life after death (Mamauag, 2019).

Since Filipinos are intrinsically family oriented as reflected in their intergenerational living arrangements, family set-up that promotes close family-ties then the elderly relies on support from family to assist their needs. They have better life, and promote a healthy and peaceful ageing journey (Chappell, 1991). Findings in this study shows that family or families of the elderly could afford some support $(\mu=72.42)$, which imply that it cannot fully provide all due to limited resources, availability, flexibility and capability of the family member as provider, and other unprecedented phenomena such as sickness of and the number of members of family needing support. Satisfaction level among the elderly varies with the family support that could influence the quality of life (Noller et al., 2013). Some of the support as reflected and identified in the study of Uddin \& Bhuiyan (2019) includes a need for love, respect, assistance in daily and religious activities. This gives useful information and emotional support, shares important decision, understands personal desires, helps to participate in social events, listen to problems, to make aware of his/her health and treatment, provides financially needs, companionships, careful of his/her food and sleep, stays happy, and overall satisfaction of the family support.

Using the World Health Organizations - Quality of Life BREF Questionnaire (WHOQOL-BREF), table 1 shows that Filipino older persons from southern Mindanao have an overall higher level of quality of life $(\mu=79.90)$ in the context of physical health, psychological, social relationships and environment. They did not reach the highest or very high QoL or score of $90 \mathrm{QoL}$ and above because of several factors which could be attributed from the family support and satisfaction of spiritual needs through church attendance. Accordingly, better outcomes of QoL among elderly is associated with strong family support and consideration of other facets of life such as spirituality (Foster, 2012).

Table 2: Church Attendance \& Family Support as Influencers of Quality of Life

\begin{tabular}{|c|c|c|c|c|c|c|c|}
\hline Variables & $R^{2}$ & $\mathbf{F}$ & B & SE (B) & $\beta$ & $t$ & $\begin{array}{c}\text { Sig. } \\
\text { (p value) }\end{array}$ \\
\hline $\begin{array}{l}\text { DV: Quality of } \\
\text { Life (QoL) }\end{array}$ & 0.20 & 0.047 & & & & & \\
\hline $\begin{array}{l}\text { IV: Church } \\
\text { Attendance }\end{array}$ & & & 2.463 & 2.577 & 0.139 & 0.956 & 0.034 \\
\hline $\begin{array}{r}\text { IV: Family } \\
\text { Support }\end{array}$ & & & -0.046 & 0.155 & -0.043 & -0.298 & 0.047 \\
\hline $\begin{array}{l}\text { DV: Church } \\
\text { Attendance }\end{array}$ & 0.17 & 0.032 & & & & & \\
\hline $\begin{array}{r}\text { IV: Family } \\
\text { Support }\end{array}$ & & & 0.008 & 0.009 & 0.131 & 0.912 & 0.036 \\
\hline \multicolumn{8}{|c|}{$\begin{array}{l}\text { Note: } n=50 . R 2=r \text { squared. } B=\text { unstandardized beta. } S E=\text { standard error. } \\
\beta=\text { standardized data. } \\
\text { sig. }=\text { Significance. } D V=\text { dependent variable. } I V=\text { independent variable. } \\
\text { level }=0.05\end{array}$} \\
\hline
\end{tabular}

Path analysis result shows that QoL is significantly influenced by church attendance and family support $\left(\mathrm{R}^{2}\right.$ $=0.20 ;$ Sig. F Change $=0.047)$. Church attendance is a positive significant predictor of $\operatorname{QoL}(\beta=0.139 ; p$ value $=0.034<0.05 \alpha$ level) while family support is a slightly negative significant predictor of QoL $(\beta=-0.043$; $p$ value $=0.047<0.05 \alpha$ level). It suggests that family support and church attendance are important components in the life of elderly that partially determines possible status of their QoL. The value of coefficient determination $\left(R^{2}=0.20\right)$ reveals in this study implies that there are other variables that has been excluded in the model, as limitation of the study, which could possibly represent about $80 \%$ as predictors or influencers of elderly's QoL. Family support as a standalone variable that could negatively influence QoL. This could be associated with the imperfect support from the family affecting the multidimensional components of their elderly's QoL and the perceived unique level of satisfaction among elderly as individual. Statistically, the limited number of participants $(n=50)$, as weakness of this study, contributes to the negative association between family support and QoL. On the side note, this study conveys 
that augmenting family support to the full may lead to betters QoL.

Moreover, church attendance is significantly predicted by family support $\left(R^{2}=0.17\right.$; Sig. $\mathrm{F}$ Change $=$ $0.032)$ and is clearly a positive significant influencer $(\beta=$ $0.131 ; p$ value $=0.036<0.05 \alpha$ level $)$ which could indicate a significant mediator between family support and QoL. It means that family providing support to their elderly shall consider assisting them in overcoming challenges and limitations to have a better church attendance to fulfill their spiritual needs, which consequently contributes positively to QoL. According to Nejati et al., (2008), alteration to or failure to meet in any or combination of those factors affects the quality of life of elderly. It accords to the study conducted by Monserud \& Markides (2017) that elderly have better life with strong social dynamics, financially supported, and have regular church attendance.

Furthermore, this study is similar to the study by Mamauag (2019) that shows that inherently elderly Christians are spiritually inclined advanced aging population of Filipinos, which follows faith in God based on their life experiences and life's meaning that affords them a sense of security and hope in the life after death. Elderly prefers closer proxemics with God which they believe that more they get involved with their spirituality at Gods kingdom (attending at church) provides them a better identification of their self and promotes deeper connection in their spiritual being. These phenomena may likewise reflected in other countries such as United States, Japan, Italy, Germany, Portugal, Finland, Bulgaria, Greece, Sweden, Latvia and Denmark growing population of elderly for generalizations. However, other factors that challenges meeting QoL among elderly must be highly considered (Humphreys, 2012) as each of them is an individual being unique and so have different aspect to consider, which relates to the World Health Organization (WHO) description of quality of life as the as "individual's discernment of their position in life in the context of the culture and values systems in which they live and in relation to their goals, expectations, standards and concerns".

\section{CONCLUSION}

The path analysis model conveys that the association between family support and church attendance and both as an independent variable are indispensable for the promotion of Filipino elderly's quality of life (QoL). The significant influence of family support towards church attendance and quality of life elderly reflects the dynamism and important role of family in providing care and in promoting a meaningful and peaceful ageing journey of their family members. This study has direct implication in the science of caring ageing population that involve dynamic family support and respecting the rights to exercise religious engagement and spirituality facilitating the possible smooth delivery of healthcare service and promotion of elderly's QoL. The phenomenal relationship of these variable must be highly considered in the plan of care. Other variables that were not covered in this study that vividly model holism of elderly's QoL are highly recommended for in-depth scientific inquiry.

\section{Conflict of Interests}

The authors declare that they have no conflict of interest.

\section{ACKNOWLEDGEMENT}

The authors are thankful to the institutional authority for completion of the work.

\section{REFERENCES}

Agli, O., Bailly, N. \& Ferrand, C. (2015). Spirituality and religion in older adults with dementia: a systematic review. Journal of International Psychogeriatrics, 27(5), pp 715-725.

Banerjee, A.T., Strachan, P.H., Boyle, M.H., Anand, S.S. \& Oremus, M., 2014. Attending religious services and its relationship with coronary heart disease and related risk factors in older adults: a qualitative study of church pastors' and parishioners' perspectives. Journal of Religion and Health, 53(6), pp.1770-1785.

Blace, N.P.J.A.S.S. (2012). Functional ability, participation in activities and life satisfaction of the older people. 8(3), 75.

Carlos, C.R. (1999). Concerns of the elderly in the Philippines. Philippine Social Sciences Review, 56(1).

Chappell, N. L. (1991). The role of family and friends in quality of life. In The Concept and Measurement of Quality of Life in The Frail Elderly (pp. 171-190): Elsevier.

Chaves, L.J. \& Gil, C.A. (2015). Older people's concepts of spirituality, related to aging and quality of life. Ciencia \& 
saude coletiva, 20, pp 3641-3652.

de Blot, P. (2011). Religion and spirituality. In Handbook of Spirituality and Business (pp. 11-17): Springer.

de Guzman, A.B., Dalay, N.J.Z., De Guzman, A.J.M., de Jesus, L.L.E., de Mesa, J.B.C. \& Flores, J.D.D. (2009). Spirituality in nursing: Filipino elderly's concept of, distance from, and involvement with God. Educational Gerontology, 35(10), pp 929-944.

de la Vega, S.A.F. (2015). Cultural validation of the WHOQOL-BREF in ambulatory community-dwelling Filipino older persons. Philippine Journal of Health Research Development, 17, 20.

Domingo, L.J. \& Asis, M.M.B. (1995). Living arrangements and the flow of support between generations in the Philippines. Journal of Cross-Cultural Gerontology, 10(1-2), pp 21-51.

Ellor, J.W. (2013). Religion and spirituality among older adults in light of DSM-5. Social Work and Christianity, 40(4), 372.

Foster, I. (2012). Wilderness, a spiritual antidote to the everyday: A phenomenology of spiritual experiences in the Boundary Waters Canoe Area Wilderness.

Gurung, S. \& Ghimire, S. (2014). Role of family in elderly care.

Hill, T.D., Burdette, A.M., Angel, J.L. \& Angel, R.J. (2006). Religious attendance and cognitive functioning among older Mexican Americans. The Journals of Gerontology Series B: Psychological Sciences, 61(1), P3-P9.

Humphreys, G. (2012). The health-care challenges posed by population ageing. In: SciELO Public Health.

Kim, M.T., Kim, K.B., Han, H.-R., Huh, B., Nguyen, T. \& Lee, H.B. (2015). Prevalence and predictors of depression in Korean American elderly: findings from the Memory and Aging Study of Koreans (MASK). The American Journal of Geriatric Psychiatry, 23(7), pp 671-683.

Lewis, M.M. (2001). Spirituality, counseling, and elderly: An introduction to the spiritual life review. Journal of Adult Development, 8(4), pp 231-240.

Malone, J. \& Dadswell, A. (2018). The role of religion, spirituality and/or belief in positive ageing for older adults. Geriatrics, 3(2), 28.

Mamauag, M.B. (2019). An Elderly's Perspective on The Impact of Spirituality Towards Death Acceptance. Belitung Nursing Journal, 5(6), pp 212-217.

McHorney, C.A., Ware Jr, J.E., Lu, J.R., \& Sherbourne, C. D. (1994). The MOS 36-item Short-Form Health Survey (SF36): III. Tests of data quality, scaling assumptions, and reliability across diverse patient groups. Medical care, pp 40-66.

Moeini, M., Sharifi, S. \& Zandiyeh, Z. (2016). Does Islamic spiritual program lead to successful aging? A randomized clinical trial. Journal of education and health promotion, 5.

Monserud, M. A. \& Markides, K. S. (2017). Changes in depressive symptoms during widowhood among older Mexican Americans: the role of financial strain, social support, and church attendance. Journal of Aging Mental Health, 21(6), pp 586-594.

Nejati, V., Shirinbayan, P., Akbari Kamrani, A., Foroughan, M., Taheri, P., \& Sheikhvatan, M. (2008). Quality of life in elderly people in Kashan, Iran. Middle East Journal of Age and Ageing, 5(2), pp 21-25.

Noller, P., Feeney, J. \& Peterson, C. (2013). Personal relationships across the lifespan: Routledge.

Noronha, K. J. (2015). Impact of religion and spirituality on older adulthood. Journal of Religion, Spirituality \& Aging, 27(1), pp 16-33.

Oates, G.L. (2016). Effects of religiosity dimensions on physical health across non-elderly Black and White American panels. Review of Religious Research, 58(2), pp 249-270. 
Pew Research. (2013). Pew Research Global Attitudes Project Spring 2013 Topline. Retrieved from: https://www.pewresearch. org/global/datasets/

Philippine Statistics Authority (2017). 2017 Philippine Statistical Yearbook. Quezon City, Philippines, Philippine Statistics Authority. Retrieved from: http://psa.gov.ph/products-and-services/publications/philippinestatisticalyearbook.

Stecz, P. \& Kocur, J. (2015). Religiousness, religious coping with illness, and psychological function among Polish elderly patients with osteoarthritis undergoing arthroplasty. Journal of religion and health, 54(2), pp 554-570.

Suárez, L., Tay, B. \& Abdullah, F. (2018). Psychometric properties of the World Health Organization WHOQOL-BREF Quality of Life assessment in Singapore. Quality of Life Research, 27(11), pp 2945-2952.

Suk Sun, K., Kim-Godwin, Y. S. \& Koenig, H. G. (2016). Family spirituality and family health among Korean-American elderly couples. Journal of Religion and Health, 55(2), pp 729-746.

Tariga, J. A. (2016). Assessment of the common predictors and their correlation in subjective wellbeing among elderly in Bohol, Philippines. The Malaysian Journal of Nursing, 8(1), pp 19-38.

Teinonen, T., Vahlberg, T., Isoaho, R. \& Kivela, S.L. (2005). Religious attendance and 12-year survival in older persons. Age Ageing, 34(4), pp 406-409. doi:10.1093/ageing/afi107

Uddin, M.A. \& Bhuiyan, A.J. (2019). Development of the family support scale (FSS) for elderly people. MOJ Gerontol Ger, 4(1), pp 17-20. doi:10.15406/mojgg.2019.04.00170 